\title{
Myeloid Sarcoma Presenting as Obstructive Jaundice
}

\author{
Matthew Patterson ${ }^{\mathrm{a}} \quad \mathrm{Yue} \mathrm{Wu}^{\mathrm{b}} \quad$ Mina Niazi ${ }^{\mathrm{c}}$ \\ aDepartment of Internal Medicine, University of Saskatchewan, Saskatoon, SK, Canada; \\ bDepartment of Pathology, University of Saskatchewan, Saskatoon, SK, Canada; \\ 'Department of Gastroenterology and Hepatology, University of Saskatchewan, Saskatoon, \\ SK, Canada
}

\section{Keywords}

Primary myeloid sarcoma - Gastrointestinal myeloid sarcoma - Obstructive jaundice

\begin{abstract}
Myeloid sarcoma (MS) is a rare solid neoplasm that consists of extramedullary myeloid precursor cells. Generally, it is associated with underlying acute myeloid leukemia (AML) or AML yet to manifest clinically. It can present as isolated, also known as primary MS without evidence of AML or other myeloproliferative neoplasms. We present the case of a previously healthy 36-year-old male, who was admitted to hospital with new-onset painful obstructive jaundice and final diagnosis of isolated MS was made after through investigations. We are pleased to report that he had favorable response to the treatment and remains well.
\end{abstract}

\section{Introduction}

Myeloid sarcoma (MS) is a tumor mass composed of myeloid precursor cells that infiltrates tissues outside of the bone marrow. Typically, MS presents concurrently with acute myeloid leukemia (AML), relapse from prior AML, or as a harbinger of AML yet to come [1]. Isolated or primary MS, defined as the presence of an extramedullary myeloblastic tumor without evidence of AML on the peripheral blood smear or bone marrow biopsy, is a rare occurrence. A retrospective study of $497 \mathrm{AML}$ patients found an incidence of $1.8 \%$ for isolated MS [2]. The diagnosis of MS is based on histopathology. MS has previously been known as chloroma due to the green color that is attributed to the expression of the enzyme myeloperoxidase (MPO). The most commonly expressed markers for MS are CD68/KP1, MPO, and CD117 [3]. MS is often misdiagnosed as malignant lymphoproliferative disorders, including 
Fig. 1. Necrotic appearing ulcer with heaped up edges surrounded by the friable irregular tissue within the duodenal bulb.

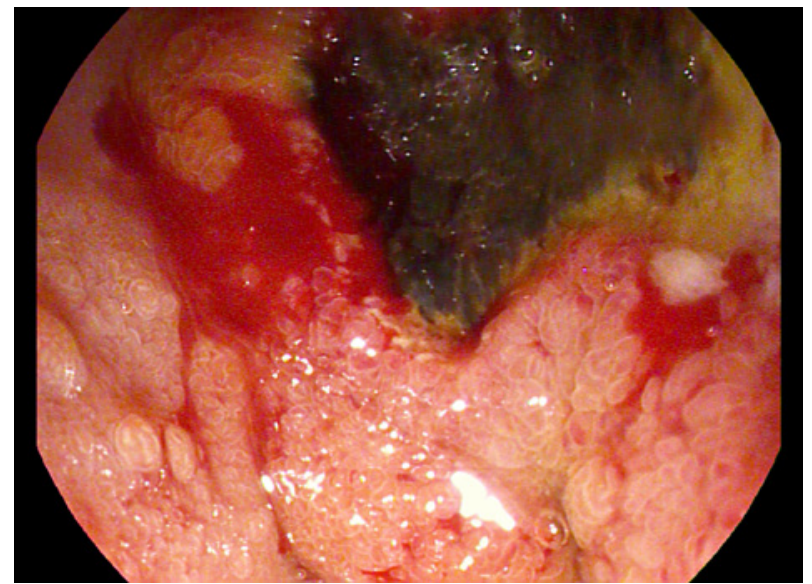

non-Hodgkin lymphomas, histiocytic lymphoma, thymoma, plasma cell myeloma, eosinophilic sarcoma, Ewing sarcoma, and carcinoma [4].

Primary MS may develop in any site of the body. It is typically reported to occur in the skin, peritoneum, bone, or lymph nodes but also infrequently develops within the gastrointestinal (GI) tract [5]. We present the case of a previously healthy 36-year-old male who presented with obstructive jaundice and later found to have primary MS isolated to the duodenum.

\section{Case Report}

A previously healthy 36-year-old male presented with 1-month history of intermittent right upper quadrant and epigastric pain, associated with postprandial nausea and vomiting. Physical exam revealed scleral icterus and jaundice. His initial vitals were stable with a temperature of $36.9^{\circ} \mathrm{C}$, heart rate of 79 , blood pressure of $142 / 88$, and $\mathrm{O}_{2}$ saturation of $95 \%$ on room air. The abdomen was soft, non-tender, and negative for Murphy's sign. Initial blood work revealed normal CBC. Alkaline phosphatase was elevated at $260 \mathrm{U} / \mathrm{L}$, alanine aminotransferase $119 \mathrm{U} / \mathrm{L}$, aspartate aminotransferase $63 \mathrm{U} / \mathrm{L}$, gamma glutamyltransferase $342 \mathrm{U} / \mathrm{L}$, and a bilirubin of $167 \mu \mathrm{mol} / \mathrm{L}$.

An abdominal ultrasound revealed gallbladder sludge, common bile duct dilation at 1.4 $\mathrm{cm}$ and 2 filling defects measuring 7 and $8 \mathrm{~mm}$ in size. Gastroscopy (EGD) revealed a moderate size clean-base ulcer in the duodenal bulb (Fig. 1). Furthermore, a cholangiogram revealed a distal common bile duct (CBD) structure measuring 2-2.5 $\mathrm{cm}$. Sphincterotomy was performed and a 9-mm CBD stent was placed. Cytology from the CBD brushings was negative. Carcinoembryonic antigen was $3.1 \mu \mathrm{g} / \mathrm{L}$ (normal 0.0-5.0 $\mu \mathrm{g} / \mathrm{L}$ ) and carbohydrate antigen 19-9 was $24.0 \mathrm{kU} / \mathrm{L}$ (normal $0.0-35 \mathrm{kU} / \mathrm{L}$ ). Biopsy of the duodenal ulcer showed duodenal mucosa with diffused infiltrates of medium-sized immature appearing cells and mixed with scattered few eosinophils. Immunochemistry demonstrated atypical cells positive for CD45, CD34, CD117, CD33, MPO, and BCL2, while negative for all the lymphoid markers, including CD163, CD68, $\mathrm{TdT}$, and CD56. The immunophenotype confirmed the presence of myeloblasts. In conjunction with their high proliferation index, a diagnosis of "duodenal mucosa with proliferation of myeloblasts compatible with myeloid sarcoma versus duodenal mucosal involvement by AML" was rendered (Fig. 2). Subsequent left iliac crest bone marrow examination revealed normocellular marrow without evidence of myeloid neoplasms or acute leukemia (Fig. 3). The concurrent peripheral blood smear did not reveal any blasts. The bone marrow cytogenetics study showed normal karyotyping. The next generation sequencing study attempted 


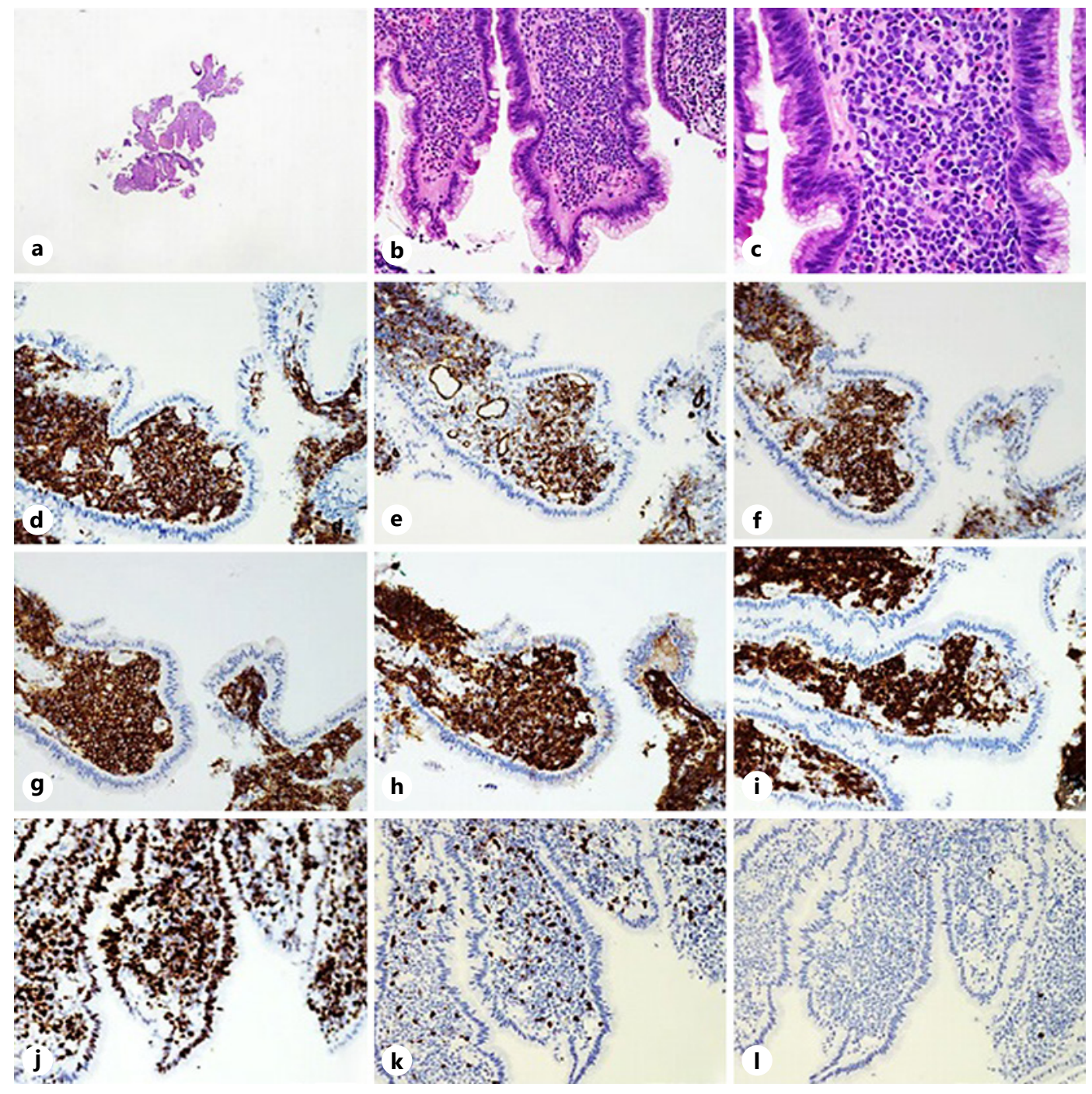

Fig. 2. Biopsy of the duodenal ulcer demonstrates duodenal mucosa with proliferation of many myeloblasts, consistent with either myeloid sarcoma or involvement by AML. a-c H and E images show proliferation of monotonous immature appearing neoplastic cells consistent with blasts (amplification at $\times 20, \times 100$, and $\times 200$, respectively). The immunostains show blasts positive for CD45 (d), variably positive for CD34 (e), positive for CD117 (f), positive for CD33, MPO, and BCL2 (g-i); negative for CD3 (k), and CD20 (I). The blasts show a high proliferation index Ki67 (j). AML, acute myeloid leukemia; MPO, myeloperoxidase.

on the paraffin block of duodenal mucosa specimen did not reveal any recurrent somatic cytogenetic abnormalities or hotspot mutations. Thus, the final diagnosis was primary or de novo MS. PET scan illustrated diffuse heterogenous activity within the abdominal ascites (SUV 6), and moderate heterogenous diffuse activity throughout the pancreas (SUV 6) suggestive of either inflammatory versus neoplastic involvement (Fig. 4). Additionally, a large mesenteric lymph node was present, measuring $2.4 \times 1.2 \mathrm{~cm}$.

Chemotherapy in the form of doxorubicin, vinblastine, and gemcitabine (AVG protocol) was initiated 11 days after his initial presentation. Cytarabine was deferred to avoid pancreatitis given patient's recent post-ERCP pancreatitis. Repeat examination to assess response to treatment was undertaken 7 weeks post initial chemotherapy. EGD and repeat biopsy of duodenal ulcer showed gastric metaplasia without evidence of dysplasia or neoplasia. 

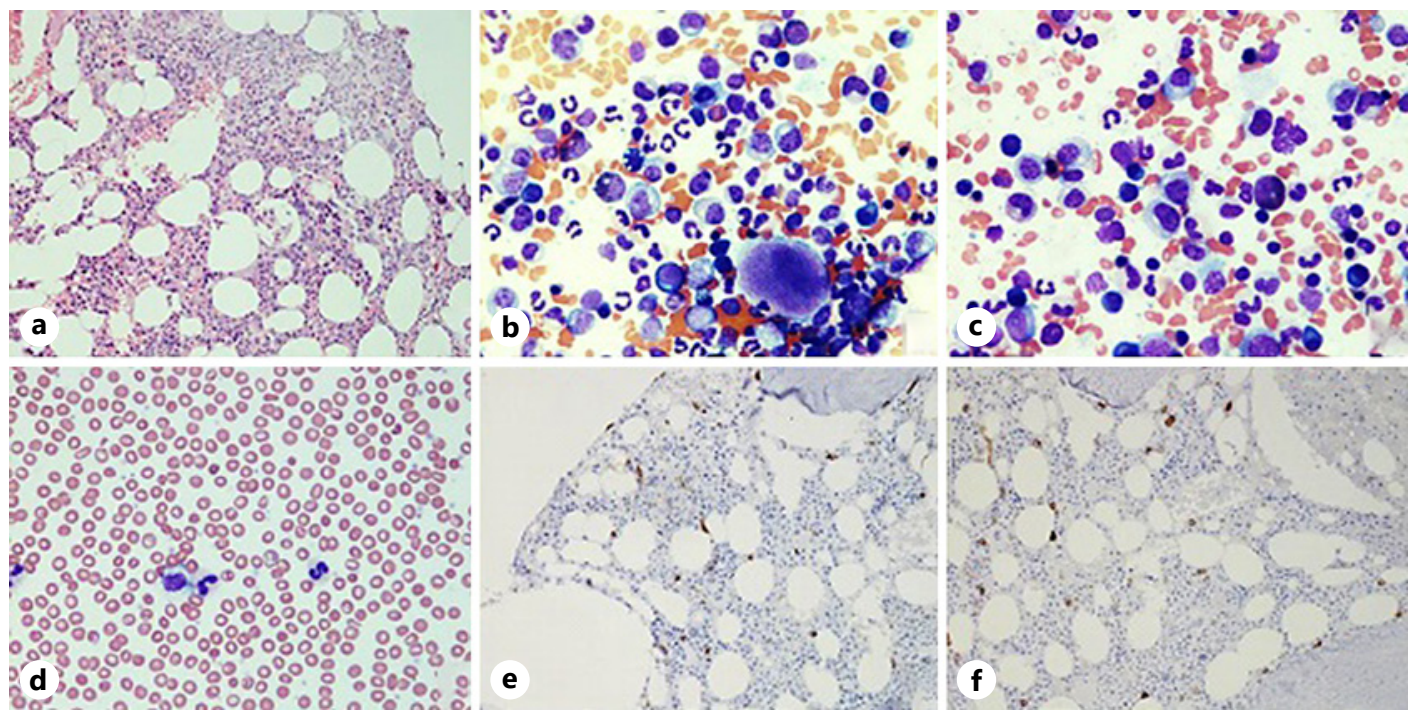

Fig. 3. Staging bone marrow examination shows maturing trilineage hematopoiesis and absence of myeloid neoplasms or AML in the bone marrow. a Bone marrow core biopsy H and E slide ( $\times 200$ amplification). b, c Bone marrow aspirate smears show slightly left-shifted myeloid cells, maturing erythroid cells, and adequate megakaryocytes ( $\times 500$ amplification). d Concurrent peripheral blood smear shows neutrophils with some toxic changes, and absence of blasts. e CD34 immunostain does not show increased blasts. f CD117 immunostain shows a few scattered mast cells only and does not show increased blasts. AML, acute myeloid leukemia.

Fig. 4. PET/CT showing mesenteric lymph node measuring $2.4 \times 1.2 \mathrm{~cm}$.

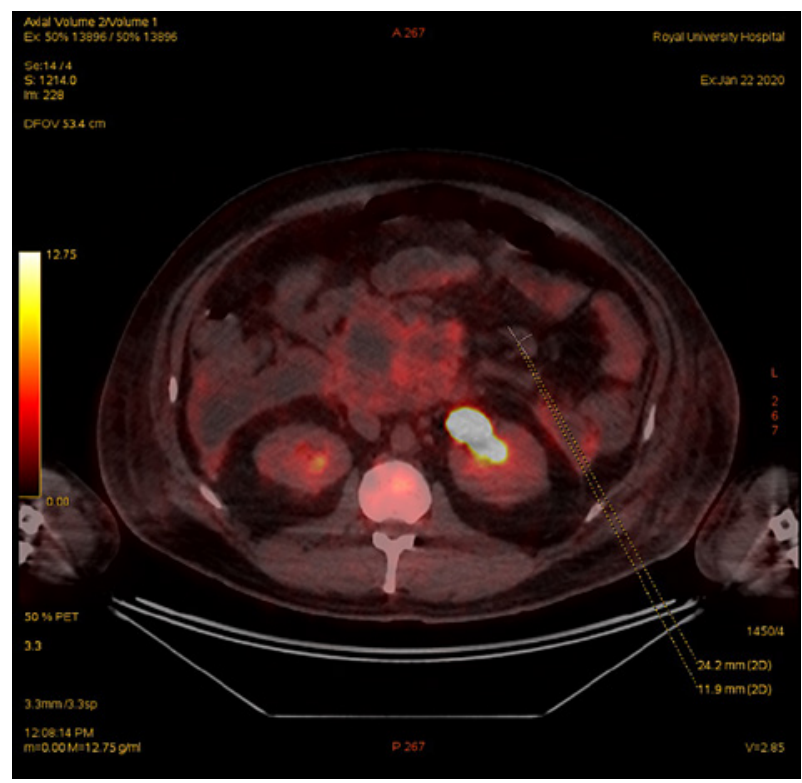

The repeat bone marrow examination revealed no evidence of myeloid neoplasm or acute leukemia. Therefore, the patient received only 1 round of chemotherapy. He was discharged home upon completion of treatment and remains in remission without progression to AML.

Four weeks after discharge, the patient was readmitted with a perforated duodenum at the ulcer site. He was taken to the operating room where he received appropriate medical and surgical treatment with an omental patch. After 2 months post-op, he underwent repeat EGD 
which did not reveal any pathology except Brunner's gland hyperplasia that was extensively biopsied. Flow cytometry analysis was performed on the specimen which was negative for the blast cells. Biopsies rather showed mild chronic inflammatory changes and, most importantly, negative for MS.

\section{Discussion \& Conclusions}

In WHO classification, MS is extramedullary malignant neoplasm and of myeloid origin [6]. While MS is most often associated with AML; it is seen to a lesser extent with chronic myeloid leukemia, myelodysplastic syndrome, and other myeloproliferative neoplasms but even rarer as a de novo occurrence $[1,2]$. The most common sites associated with isolated MS are the skin (28-36\%), lymph nodes (13-16\%), testis (2.9-6.5\%), intestine (6.5-8.9\%), bone (3.3-4.9\%), and central nervous system $(3.2 \%)[3,7]$. Case reports have been published showing primary MS involving GI tract and associated organs that include the stomach [8-11], gallbladder [12], pancreas [13], small intestine [14-19], colon [20], and mesentery [21]. These articles have been summarized in Table 1 . These cases include MS only affecting the GI organs with no progression to AML at least by the time of their publication.

The diagnosis of primary MS is difficult with a rate of misdiagnosis ranging from 25 to $75 \%$ [22-24]. The most common misdiagnoses are malignant lymphoproliferative disorders, including non-Hodgkin lymphoma, histiocytic lymphoma, thymoma, plasma cell myeloma, eosinophilic sarcoma, Ewing sarcoma, and carcinoma [4]. The tissue biopsy of primary MS reveals infiltration of blasts of myeloid lineages and immunohistochemistry staining shows the blasts positive for the stem cell markers (CD34 and CD117) and myeloid cell lineage markers (CD33, MPO, CD68, CD163, etc.). A bone marrow biopsy and peripheral blood smear should be completed to rule out the underlying AML and other hematological malignancies [6].

Isolated MS can occur following, concurrently, or preceding a diagnosis AML. MS always progresses to AML within 3-6 months but this period is noted to be longer in those receiving chemotherapy [22]. Many studies have shown that isolated MS responds to AML chemotherapy protocols [25-28]. The typical AML chemotherapy regimens include combinations of idarubicin, cytarabine, fludarabine, daunorubicin, granulocyte colony-stimulating factor, and cyclophosphamide [26]. One study has shown that chemotherapy alone was less successful than chemotherapy plus hematopoietic stem cell transplant; however, the study was small with only 12 patients from a single center [23]. Radiotherapy and debulking surgery can be used as adjuncts but should never take the place of systemic chemotherapy [27-29]. Furthermore, the primary tumor sites have implications on patient outcomes including mortality. MS isolated to the pelvis/GU organs had the highest 12 month survival at $81 \%$ compared to the soft tissue involvement at $26 \%$ and GI involvement having intermediate survival at $61 \%$ [7].

Of the cases listed in Table 1, individuals with primary MS of the GI tract were on an average 47 years old at diagnosis, and $58 \%$ male. $58 \%$ of the individuals were still alive by the time the case was published. Of those that died, $66 \%$ had gastric involvement. The most common treatment for primary GI MS that did not progress to AML was the standard chemotherapy for AML alone which includes cytarabine, daunorubicin, and etoposide. Complications of primary GI MS include small bowel obstruction, ascites, and perforated viscus [30-32]. Comparing the literature to the case we presented here illustrates some notable differences. First, our patient was 36 years old at the time of diagnosis compared to the average age of 47 . Second, of the cases listed in Table 1 most patients with GI involvement presented with either abdominal pain or bowel obstruction whereas our patient's presenting concern was obstructive jaundice. Last, our patient went into remission despite cytarabine being excluded from the standard AML treatment due to the increased risk of pancreatitis, given his post-ERCP pancreatitis [33].

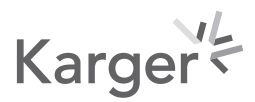


Patterson et al.: Myeloid Sarcoma Presenting as Obstructive Jaundice

Table 1. Summary of adult cases published with de novo MS involving the GI tract

\begin{tabular}{|c|c|c|c|c|}
\hline Derenzini et al. [11] & $40 / \mathrm{M}$ & $\begin{array}{l}\text { Stomach and } \\
\text { duodenum }\end{array}$ & Standard AML Chemotherapy & Alive at publication \\
\hline Kwan et al. [14] & $39 / F$ & Terminal ileum & $\begin{array}{l}\text { Ileal resection and standard } \\
\text { AML chemotherapy }\end{array}$ & $\begin{array}{l}\text { Alive and no recurrence } \\
\text { of disease }\end{array}$ \\
\hline Narayan et al. [15] & $48 / \mathrm{M}$ & Duodenum & $\begin{array}{l}\text { Standard AML chemotherapy } \\
\text { and radiation therapy }\end{array}$ & $\begin{array}{l}\text { Alive and no recurrence } \\
\text { of disease }\end{array}$ \\
\hline Vachhani and Bose [10] & $52 / \mathrm{F}$ & Stomach & $\begin{array}{l}\text { Standard AML chemotherapy } \\
\text { and radiation therapy }\end{array}$ & $\begin{array}{l}\text { Died to metastatic } \\
\text { disease }\end{array}$ \\
\hline Ohanian et al. [21] & $54 / \mathrm{M}$ & Mesentery & Standard AML chemotherapy & $\begin{array}{l}\text { Alive and no recurrence } \\
\text { of disease }\end{array}$ \\
\hline Yu et al. [8] & $31 / \mathrm{F}$ & $\begin{array}{l}\text { Stomach and } \\
\text { duodenum }\end{array}$ & $\begin{array}{l}\text { Standard AML chemotherapy } \\
\text { and radiation therapy }\end{array}$ & $\begin{array}{l}\text { Died to metastatic } \\
\text { disease }\end{array}$ \\
\hline Huang et al. [9] & $38 / \mathrm{M}$ & Stomach & Standard AML chemotherapy & $\begin{array}{l}\text { Alive and no recurrence } \\
\text { of disease }\end{array}$ \\
\hline Ocak et al. [16] & $37 / \mathrm{M}$ & $\begin{array}{l}\text { Jejunum and } \\
\text { mesentery }\end{array}$ & $\begin{array}{l}\text { Jejunum and descending } \\
\text { colon resection, and standard } \\
\text { AML chemotherapy }\end{array}$ & $\begin{array}{l}\text { Alive and no recurrence } \\
\text { of disease }\end{array}$ \\
\hline Holzwanger et al. [12] & $74 / \mathrm{F}$ & Gall bladder & Cholecystectomy & $\begin{array}{l}\text { Died at presentation } \\
\text { secondary to sepsis }\end{array}$ \\
\hline Yoshida et al. [17] & $47 / \mathrm{M}$ & $\begin{array}{l}\text { Ileum and } \\
\text { appendix }\end{array}$ & $\begin{array}{l}\text { Ileal and appendiceal } \\
\text { resection, and unstated } \\
\text { type of chemotherapy }\end{array}$ & Unknown \\
\hline Aslan et al. [18] & $57 / F$ & Ileum & Ileal resection & Unknown \\
\hline Mizumoto et al. [19] & $54 / \mathrm{M}$ & Jejunum & $\begin{array}{l}\text { Jejunal resection and standard } \\
\text { AML chemotherapy }\end{array}$ & $\begin{array}{l}\text { Alive and no recurrence } \\
\text { of disease }\end{array}$ \\
\hline
\end{tabular}

Reports with preceding, concurrent or subsequent AML were excluded. Standard chemotherapy for AML refers to cytarabine, daunorubicin, and etoposide.

MS, myeloid sarcoma; GI tract, gastrointestinal tract; AML, acute myeloid leukemia.

Finally, our case highlights complications and morbidity of primary MS. Not only did our patient developed pancreatitis but experienced perforated viscus. While primary MS involving the GI tract does not have the highest mortality of all the potential organ involvements, it is significant with a 12-month mortality of 39\% [7].

\section{Acknowledgements}

We thank our patient for providing consent for publication of this case for the purpose of learning and advancing medicine.

\section{Statement of Ethics}

The following research complies with the guidelines for human studies and was conducted ethically in accordance with the World Medical Association Declaration of Helsinki. The patient provided informed written consent to publish their case including the publication of the images. 
Patterson et al.: Myeloid Sarcoma Presenting as Obstructive Jaundice

\section{Conflict of Interest Statement}

The authors have no conflict of interests to declare.

\section{Funding Sources}

The authors were not provided with any funding relevant to this publication.

\section{Author Contributions}

Matthew Patterson was involved in drafting the manuscript. Yue Wu was involved in interpreting the pathology and revision of the manuscript. Mina Niazi was involved in revision and approval of the final version of the manuscript.

\section{References}

1 Campidelli C, Agostinelli C, Stitson R, Pileri SA. Myeloid sarcoma: extramedullary manifestation of myeloid disorders. Am J Clin Pathol. 2009;132(3):426-37.

2 Lee JY, Chung H, Cho H, Jang JE, Kim Y, Kim SJ, et al. Clinical characteristics and treatment outcomes of isolated myeloid sarcoma without bone marrow involvement: a single-institution experience. Blood Res. 2017;52(3): 184-92.

3 Pileri SA, Ascani S, Cox MC, Campidelli C, Bacci F, Piccioli M, et al. Myeloid sarcoma: clinico-pathologic, phenotypic and cytogenetic analysis of 92 adult patients. Leukemia. 2007;21(2):340-50.

4 Yilmaz AF, Saydam G, Sahin F, Baran Y. Granulocytic sarcoma: a systematic review. Am J Blood Res. 2013;3(4): 265-70.

5 Neiman RS, Barcos M, Berard C, Bonner H, Mann R, Rydell RE, et al. Granulocytic sarcoma: a clinicopathologic study of 61 biopsied cases. Cancer. 1987;48(6):1426-37.

6 Vardiman JW, Thiele J, Arber DA, Brunning RD, Borowitz MJ, Porwit A, et al. The 2008 revision of the World Health Organization (WHO) classification of myeloid neoplasms and acute leukemia: rationale and important changes. Blood. 2009;114(5):937-51.

7 Movassaghian M, Brunner AM, Blonquist TM, Sadrzadeh H, Bhatia A, Perry AM, et al. Presentation and outcomes among patients with isolated myeloid sarcoma: a surveillance, epidemiology, and end results database analysis. Leuk Lymphoma. 2015 Jun 3;56(6):1698-703.

8 Yu T, Xu G, Xu X, Yang J, Ding L. Myeloid sarcoma derived from the gastrointestinal tract: a case report and review of the literature. Oncol Lett. 2016;11(6):4155-9.

9 Huang XL, Tao J, Li JZ, Chen XL, Chen JN, Shao CK, et al. Gastric myeloid sarcoma without acute myeloblastic leukemia. World J Gastroenterol. 2015;21(7):2242-8.

10 Vachhani P, Bose P. Isolated gastric myeloid sarcoma: a case report and review of the literature. Case Rep Hematol. 2014;2014:1-4.

11 Derenzini E, Paolini S, Martinelli G, Campidelli C, Grazi GL, Calabrese C, et al. Extramedullary myeloid tumour of the stomach and duodenum presenting without acute myeloblastic leukemia: a diagnostic and therapeutic challenge. Leuk Lymphoma. 2008;49(1):159-62.

12 Holzwanger EA, Alam Z, Hsu E, Hsu A, Mangano M, Kathman DL. A case of granulocytic sarcoma or extramedullary acute myelomonocytic leukemia of the gallbladder. Am J Case Rep. 2018;19:1262-6.

13 Breccia M, D’Andrea M, Mengarelli A, Morano SG, D’Elia GM, Alimena G. Granulocytic sarcoma of the pancreas successfully treated with intensive chemotherapy and stem cell transplantation. Eur J Haematol. 2003;70(3): $190-2$.

14 Kwan LY, Targan SR, Shih DQ. A case of steroid-dependent myeloid granulocytic sarcoma masquerading as Crohn's disease. World J Gastroenterol. 2011;17(19):2446-9.

15 Narayan P, Murthy V, Su M, Woel R, Grossman IR, Chamberlain RS. Primary myeloid sarcoma masquerading as an obstructing duodenal carcinoma. Case Rep Hematol. 2012;2012:490438-7.

16 Ocak S, Alakus H, Duymus M, Kaya M, Karadayi K, Yeldir N, et al. Nonleukemic myeloid sarcoma presenting as intussusception of small bowel in a male patient: an unusual presentation. Transl Surg. 2016;1(2):48.

17 Yoshida M, Ogami T, Morgenstern N, Du L. Myeloid sarcoma resulting in a small bowel obstruction with multiple site involvement including ileum and appendix. J Surg Case Rep. 2019;2019(9):rjz248-3.

18 Aslan B, Tüney D, Erçetin Y, Bozkurt SU, Uprak TK. De novo myeloid sarcoma as a rare cause of small bowel obstruction: CT findings and histopathologic correlation. Radiol Case Rep. 2019;14(12):1487-90. 
Patterson et al.: Myeloid Sarcoma Presenting as Obstructive Jaundice

19 Mizumoto R, Tsujie M, Wakasa T, Kitani K, Manabe H, Fukuda S, et al. Isolated myeloid sarcoma presenting with small bowel obstruction: a case report. Surg Case Rep. 2020;6(1):2-7.

20 Gorczyca W, Weisberger J, Seiter K. Colonic adenomas with extramedullary myeloid tumor (granulocytic sarcoma). Leuk Lymphoma. 1999;34(5-6):621-4.

21 Ohanian M, Huang RSP, Yakoushina TV, Estrov Z, Juneja H, Chen L, et al. Isolated mesenteric CD20-positive myeloid sarcoma. Clin Lymphoma Myeloma Leuk. 2014;14(6):e217.

22 Meis JM, Butler JJ, Osborne BM, Manning JT. Granulocytic sarcoma in nonleukemic patients. Cancer. 1986; 58(12):2697-709.

23 Antic D, Elezovic I, Milic N, Suvajdzic N, Vidovic A, Perunicic M, et al. Is there a "gold" standard treatment for patients with isolated myeloid sarcoma? Biomed Pharmacother. 2013;67(1):72-7.

24 Yamauchi K, Yasuda M. Comparison in treatments of nonleukemic granulocytic sarcoma: report of two cases and a review of 72 cases in the literature. Cancer. 2002;94(6):1739-46.

25 Tsimberidou AM, Kantarjian HM, Wen S, Keating MJ, O’Brien S, Brandt M, et al. Myeloid sarcoma is associated with superior event-free survival and overall survival compared with acute myeloid leukemia. Cancer. 2008 Sep 15;113(6):1370-8.

26 Almond LM, Charalampakis M, Ford SJ, Gourevitch D, Desai A. Myeloid sarcoma: presentation, diagnosis, and treatment. Clin Lymphoma Myeloma Leuk. 2017;17(5):263-7.

27 Bakst RL, Tallman MS, Douer D, Yahalom J. How I treat extramedullary acute myeloid leukemia. Blood. 2011 Oct 6;118(14):3785-93.

28 Avni B, Koren-Michowitz M. Myeloid sarcoma: current approach and therapeutic options. Ther Adv Hematol. 2011 Oct 1;2(5):309-16.

29 Bakst R, Wolden S, Yahalom J. Radiation therapy for chloroma (granulocytic sarcoma). Int J Radiat Oncol Biol Phys. 2012;82(5):1816-22.

30 Palanivelu C, Rangarajan M, Senthilkumar R, Annapoorni S. Laparoscopic management of an obstructing granulocytic sarcoma of the jejunum causing intussusception in a nonleukemic patient: report of a case. Surg Today. 2009;39(7):606-9.

31 Choi EK, Ha HK, Park SH, Lee SJ, Jung SE, Kim KW, et al. Granulocytic sarcoma of bowel: CT findings. Radiology. 2007;243(3):752-9.

32 Lai PBS. Granulocytic sarcoma of the small bowel causing intestinal obstruction. Hong Kong Med J. 2005; 11(3):204-6.

33 Kahaleh M, Freeman M. Prevention and management of post-endoscopic retrograde cholangiopancreatography complications. Clin Endosc. 2012;45(3):305. 